\title{
Didactic Communication and the Development of Communicative Skills - A Primordial Factor in Education
}

\author{
${ }^{1}$ Chiriac Argentina, ${ }^{1}$ Trebeș Tatiana, ${ }^{1}$ Lopatiuc Alina and ${ }^{2}$ Guțu Vladimir \\ ${ }^{1}$ The State University of Medicine, \\ ${ }^{2}$ The State University of Republic of Moldova
}

\begin{abstract}
The communication in the process of education is an important factor which involves the skills of communication between teacher and student/group. An efficient communication between teacher and student during the lesson is the key to a successful way of getting knowledge and achieving the main goal. That's why all teachers' activities must be very well thought in such way that the student could develop his communicative skills being involved in the process of education.
\end{abstract}

\section{Introduction}

The goals of modern education strategically lines define education development/education relevant economic developments, political, cultural, commutate of postmodern society.

Provides built plural derivation objectives in terms of education policy through action targeting the educational process at global normative (general objectives) and practical (general objectives include developing curriculum. These criteria for defining strategic directions of the modern education are necessary to wide education system.

The idea of this education defines the type of personality that is necessary for society, education system designed to scale. This ideal of contemporary education is not a standard imposed forever, but a dynamic model that allows resizing.

\section{Literature review}

After Cucos [3], the educational ideal is a value resort that radiates name, principles, strategies, goals, and objectives determined that directs the training of young generations. Author arguing that educational ideal in itself is not functional only if it allows. Educational ideal educational realities determined to follow a route value.

Higher education institutions also contribute greatly to achieving the educational ideal, expressing the highest degree and harder to achieve perfection in a certain area, which tends to model the entire human being in its activity.
It tends to mean ideal to aspire to perfection, perfection. When referring to the pedagogical ideal, S. Cristea argues that current pedagogical ideal aimed at forming a creative personality and autonomous, adaptable to hanging conditions innovative rapid information specific type post-industrial society "he notes that educational goals are outcomes of macrostructural determined pedagogical ideal, guiding the actions of training - personality development designed and made in the education system.

\section{Research Methodology}

Referring to the educational goals, we deduce that they depend on the purpose of education, representing more concrete elaborations of it. Specifically, the objectives are to "what the teacher claims to obtain from his students: apply the principles, methods, and processes, analyze ways to maintain social relationships with people or with certain special groups.

Human activity content of each is sharing information between persons view to establishing and maintaining relations of cooperation and mutual understanding through language is communication, which has an imperative role in the development of modern education.

Related communication can follow two objectives: one cognitive (because we want to send the listener to communicate certain information) and other social considerations (when communication is directed towards specific outcomes) will describe the basic features of communication.

Being organized and conducted in accordance with philosophical challenges from different times, modern education focuses on knowledge, skills, and habits on training, on cultivating attitudes and intellectual capacities.

These statements guide us to reverse the process of preparation and teacher in foreground situ the formation of skills, attitudes, and abilities spiritual, moral and ethical, then the accumulation of knowledge and professional skills so we can focus and 
degree quality of social interaction between teacher and student.

In forming competence and communication skills in the vocational training it is important to know the requirement that makes us have morality, responsibility towards others personality. Every individual has the possibility to cultivate and to make better use of their capacities and skills to integrate into modern society.

In Cucos's opinion the didactic communication is a complex, variable transfer of information through different ways between two entities (teacher- student, or teacher-group of students), meaning the important contents in the process of education. Both, the student and teacher are responsible for what and how they communicate. The educational communication is supposed to have an interaction between actors, a feedback during the discussion from explicit and new information.

A very common term which we meet in different works about education we found also in Iacob's work which affirms that educational communication is an instrumental one, directly implied in supporting a systematic process of studying, the specific effect of communication is determined by the institutional side in which an important role have logic and studying. So, the didactical communication is a fundamental modality of activity teaching-studying of some specific contents, being codified; the relationship between teacher and student (group) has a major role in the adaptive and formative value.

The meeting of the teacher with the student supposes a dialog between two centers of intentions and interests, but the education has, as a result, the formation of a new center which will allow the continuation of the dialog.

In the opinion of Cristea, the communication in education represents an axiomatical principle of activities of teaching, which involves an educational message, elaborated by subject (teacher) able to challenge the reactions of the object of education (pupil, student). The evolution of this concept of communication in education set up the existence of 3 directions:

The emphasizing of the role of the subject in education, which think about contents, about auditory, about ways of communication depending on the psychology of each group according to the age and according to social peculiarities.

The emphasizing of the object of education, in order to put on the first place the psychology of students.

The direction of development of relationships between teacher and students engaged in cognitive and affective, motivational, verbal and nonverbal process.

Speaking about students' communication we can conclude that there are different peculiarities. It has mentioned aspects of education orientation and the studying of personality formation through education and learning methodology and procedures by learning how practice a research. Attainments in education are necessary but not sufficient. Knowledge is old, but if students have their art enrichment, will face life easier.

Education must anticipate the development of society, assuming the formation of the person capacity decision-making social responsibility of forecasting activities in different living conditions, analysis of the actions, deeds of self and others and forming a flexible behavior, adaptable new socioeconomic conditions.

Forward future demands of increasingly high. These requirements require changes, these changes depend on the trends that will guide the development of new educational policy.

Cristea internal reports that one of the characteristics of education policy is the perspective character "highlights that the education activities aimed always a future situation, potential, strategically superior to the present, current circumstantial” [4].

Education components have been redesigned with the development that has met all fields.

And as Kant said, "It's nice to think that human nature will be best developed through education and that can get him to give shape to suit him. This reveals the prospect of future happiness of mankind" [1].

The prospective forms of education are to open personality, autonomous, adaptable to changes in the type of innovative, although there is the other side of things, changing what is known of things, man changing the world we know. Changing world in which man lives change himself [2].

Within higher education, adult, communication is a major factor, especially in the teaching/learning languages. We say that the development of communication skills is an imperative of this because communication is the very power which permits a person to act using inter linguistic, using means these means is guided, trained and developed both the person and the teacher it is engaged in language education of the person. Teachers use various methods and including the communicative method.

A communicative method in teaching a foreign language is based on some fundamental principles:

- Individualization;

- Novelty;

- Functionality

- Situation (Teaching Learning through communication, p. 40)

Individualisation takes the capabilities of the person being trained, such as memory capacities performing tasks etc. Here we can include character platforms because there are people affective (based on their own emotions and feelings) and are rational people (leading to logical arguments). Perception of linguistic structures will be individual to each person, 
but cannot provide individual qualities communicative motivation.

The novelty or timeliness involves using current topics and methods will be innovative and interactive. The lesson will be based on discussions. maximum involvement of actors and issues discussed will be the permanent change in line with changes in society. Novelty aimed at communication and exchange participants, clustering the novelty of topics and intuitive technical means.

When it comes to communication, we cannot ignore the situation because it is an indispensable quality of speech. It allows people to adapt and communicate in various situations. The best method for developing mechanisms and qualities of speech communication situations are unconditional.

Functionality is more about the use of words, phrases joints word on which forms communicative models.

The functionality also requires speech reproductive methods (already memorized) and productive units (created by the intent speaker, and the manner and forms of organizing the material must be functionally oriented to communicative purpose.

To achieve certain communicative intentions, users mobilize general skills as above and combines them with a linguistic communicative competence.

Communicative competence CD comprises the following components:

- Language skills;

- $\quad$ Sociolinguistic competence;

- $\quad$ Pragmatic skills;

At present, there is no universally accepted theory of general linguistics. The language is highly complex and, in the case of a vast, diverse and advanced, is never fully mastered by any of its users. Otherwise, it is not going to happen this because each language is a constantly evolving to meet the demands of its use in communication. Most nation states have attempted to define a rule without coming în details. To a presence, it has used the model of linguistic description in use for teaching hardened corpus of literary texts that served as support learning dead languages. This model of "traditional" was however rejected, now more than a hundred years by the most illustrious linguists who claimed that languages should be described in the way they work really, not the way a certain authority would like to see; the traditional model, developed for a certain type of language was inappropriate to describe some language system based on a very different organization. However, none from other proposed as alternative models was not accepted unanimously. In fact, the possibility of a single universal model description language was rejected. Recent work on universals has yet meaningful results to facilitate learning, teaching, and evaluation of languages. Most linguists descriptivist limited henceforth to codify the practice, putting in report form and meaning and using terminology that departs from traditional practice only when treating phenomena outside the range of traditional models of description. This approach is adopted Section

It covers the major identification and classification of the main components of language proficiency, defined as formal knowledge resources, on which can be developed and made accurate and meaningful messages and the identification of capacity to use them. The plan aims to present the following, as a tool for classification, some parameters, and categories which may prove useful in describing a linguistic content and as a basis for reflection. Practitioners who would prefer to use a different frame of reference should feel free to do so in this case as in others. In this situation, they should identify the theory, tradition, and practice that we adopt. We distinguish here:

- Lexical competence, that is the competence in understanding words, and a component of general semantic competence (competence in understanding language). In Marconi’s opinion the lexical competence must be divided into inferential competence (the ability to draw materially good inferences involving words) and referential competence (the ability to apply words to objects, to name them).

- Grammatical competence or the ability to organize phrases to send a message. This is the core, the nucleus of the communicative competence; organize phrases for sending a message. It is the nucleus of the communicative competence.

- Semantic competence that involves the speaker's ability to establish semantic relationships (sense and meaning) between morphological and syntactic units: relationship of including (containing) of the sense (is part of etc.), of referring, of consistency, of coherence.

- Phonological competence that involves students' ability to recognize and to reproduce/imitate the distinctive meaningful sounds of a language: vowels, consonants, syllables, tone, intonation, rhythm and stress patterns or any other suprasegmental features that carry meaning. Related to phonological competence are the orthographic competence and the orthoepic competence which deals with the spell power.

- Sociolinguistic competence refers to knowledge and skills to harness the social dimension of language functioning. As we pointed out in connection with sociocultural competence, and since language is a social phenomenon, the essence of what is presented in the framework of reference, particularly as regards the sociocultural field, could be considered. They will be treated specifically, and the use of language issues has not been addressed elsewhere. 
- Indicators of social relations

Communication stands in a universal means- ends relation to human collective activities. As soon as human beings need to be coordinated in a joint activity, joint information is needed for the coordination. The information becomes joint by communication which is mostly linguistic. The communication must be verbally linguistic in such activities as discussing, debating or negotiating but can be of other kinds, e.g., nonverbal, in activities such as joint hunting or joint ploughing of the fields. However, whether verbal or not, there is always communication as soon as we have coordinated activity and this communication is frequently verbally linguistic, even in the cases where other types of communication are possible.

- The rules of politeness

The concept of politeness is a part of a vast sociopragmatic phenomenon that has a fundamental impact on the way we communicate and the way we relate ourselves to the people around us and to ourselves. The rules of politeness have some important functions they permit people to avoid the conflicts, to be nice, to manage the impression about the speaker and in general about the subject. Politeness is often a persuasive strategy, designed to influence someone to respond more favorably to your message or to gain someone's compliance. The forms that politeness can take in a specific society vary enormously. That's why politeness must be understood as "a sum of all tactics that help people to maintain a minimum level of harmony during communication.” Politeness is also a multidimensional, a dynamic, and a constant manifestation at the discursive level. It will vary from one situational context to another, from one region to another and it depends on sociolinguistics parameters such as the distance between interlocutors, the distribution of power, the social and cultural medium of the speakers and their cognitive load. This is why politeness is one of the most important factors in developing sociocultural competence.

- Expressions of popular wisdom

Proverbs represent a cultural material highly diversified. Due to their mnemotechnic role, they are identified with a concise linguistic formula that has firm syntactic structures, easy to be inventoried, and a polysemantic vocabulary, that expresses the result of an ancestral life experience and that implies the study of the language in a cultural/sociocultural context in which it is used. Including elements of folklore, psychology, linguistics, sociolinguistics and history proverbs or other expressions of popular wisdom give to the discourse an interesting connotation. In this case, the listeners will be more interested in the information and the studying will become more interesting.

\section{- Differences in register}

The linguistic register is a variety of language, that is manifested in the process of speaking, and that is socially and culturally determined. Linguistic registers (formal, informal, familiar, popular, archaic, pejorative) are considered linguistic sub-codes that are chosen consciously or spontaneously within a sociolinguistic community. It is important to know the differentiation between linguistic registers because they determine the social dimension of language use. Speaking about the linguistic registers and taking into consideration that teenagers have a slang language and they used to speak in a different way, the teacher must make some exercises for making the speech more cultural and correct.

- Dialect and accent

The accent of somebody always leads us to the nationality of the person. The teacher must not be interested in this topic because it is anti-pedagogical.

\section{- Pragmatic competence}

The pragmatic competence presupposes the preparation of sending the message in a specific communicative situation. It also implies the functional utilization of all linguistic resources (realization of the communicative functions, of the speech acts), relying on schemes or descriptors of interactional exchanges. The pragmatic competence includes the discursive competence, the ability of the speaker to make sentences and to arrange them in a sequence that will respect the rules of the discourse organization. The cohesion and the coherence of a discourse depend on the pragmatic competence of the speaker, that's why this competence is very important in the development of the communicative competence that implies the reception, production, interaction, and mediation of a communicative situation. Therefore, the pragmatic competence refers to knowledge by the user/student of the principles according to which messages are:

a. organized, structured and tailored (discursive competence);

b. used to perform communicative functions (functional competence).

c. segmented according to interactional and transactional scheme (schematic design power)

\section{Conclusion}

We live in a world where the communication is an important condition of being. All people need communication and it does not matter which kind of communication it is. We can communicate in a real or virtual world, in written form or oral, even an art is a way of communication. In high education, we need to teach communication through other subjects. In teaching languages, we teach Grammar, phonology, etc. And of course, communication, because the communicative competencies must consist from 
expressing wants and needs, develop social closeness, exchange information and fulfill the social etiquette

\section{References}

[1] Cardella-Elawar M., (1992). The metacognitive teacher.

[2] Cucos C., (2000). Dimensiuni culturale şi interculturale, ed. Polirom.

[3] Klippel F., (1993). Keep talking, communicative fluency activities for language teaching, Cambridge Universiy Press, Cambridge.

[4] Marconi D., (1997). Lexical Competence, MIT Press, Cambridge, Mass-London. 